\title{
DIGESTIBILIDADE DA MATERIA SECA E PARÂMETROS DA FERMENTAÇÃO IN VITRO DE PLANTAS FORRAGEIRAS
}

\section{(Digestibility of dry matter and parameters in vitro fermentation of forage plants)}

\author{
Luiz Juliano Valério Geron ${ }^{1}$, Matheus Gonçalves Ribeiro, Silvia Cristina Aguiar, Maria \\ Aparecida Pereira Pierangeli, Ana Paula da Silva, Roberto Silve \\ 1 Correspondência: ljgeron@yahoo.com.br
}

RESUMO: Objetivou-se avaliar a digestibilidade da matéria seca (MS) e os parâmetros da fermentação in vitro de plantas forrageiras in natura e ensiladas no período da seca por meio da técnica de 24 horas de incubação. As plantas forrageiras avaliadas foram Brachiaria brizantha cv. Marandu; Brachiaria humidicola; Panicum maximum cv. Mombaça; Panicum maximum cv. Massai; silagem de milho (Zea mays); silagem de sorgo (Sorghum bicolor L. Moench); cana -de- açúcar (Saccharum officinarum L) picada in natura. Foi utilizado um delineamento experimental inteiramente casualizado (DIC), sendo consideradas como repetições de campo três baterias para a determinação da DIV da MS das forrageiras. A análise estatística das variáveis estudadas foi interpretada por meio de análise de variância e quando observada diferença aplicou-se o teste de Tukey a $5 \%$ de significância. Não houve $(P>0,05)$ diferença significativa dentro dos gêneros das diferentes espécies forrageiras ou nos volumosos suplementares (silagem). Os valores da digestibilidade in vitro (DIV) da MS para os capins do gênero Brachiaria foram de $48,40 \%$ para o capim-marandu e 51,21\% para capim-humidícola. Para o gênero Panicum os valores da DIV da MS foram de $46,70 \%$ e $40,49 \%$, respectivamente, para o capim-mombaça e massai. Para os volumosos ensilados (silagem de milho e silagem de sorgo) e a capineira (cana-de-açúcar) observaram-se os valores de 63,22\%, 54,00\% e 59,76\% da DIV da MS, respectivamente. Não houve $(P>0,05)$ alteração nos valores de $\mathrm{pH}$ e na concentração do nitrogênio amoniacal durantes a fermentação in vitro das plantas forrageiras. Assim, conclui-se, que o valor da DIV da MS e os parâmetros da fermentação in vitro se mantem similar para os capins do mesmo gênero e forrageiras ensiladas no período da seca.

Palavras-chave: fermentação, pH; nitrogênio amoniacal; volumoso suplementar

\begin{abstract}
This study aimed to evaluate the digestibility of dry matter (DM) and the parameters of the in vitro fermentation of forage plants in natura and ensiled in the dry season by the technique of 24 hours of incubation. The plants forage evaluated were Brachiaria brizantha cv. Marandu; Brachiaria humidicola; Panicum maximum cv. Mombasa; Panicum maximum cv. Massai; silage corn (Zea mays); sorghum (Sorghum bicolor L. Moench); sugar cane (Saccharum officinarum L) chopped in natura. Was used one completely randomized design (CRD), being considered as repetitions of the field three batteries for determining the DIV of DM of the fodders. Statistical analysis of variables was performed using analysis of variance and when observed differences was applied the Tukey test at $5 \%$ significance. There was no $(P>0.05)$ significant difference within the genres of different forage species or supplementary roughage (silage). The values of digestibility in vitro (DIV) of DM for grasses of the genres Brachiaria were $48.40 \%$ for the marandu grass and $51.21 \%$ for humidicola grass. For the genus Panicum the values of the DIV of DM were $46.70 \%$ and $40.49 \%$, respectively, for the mombasa and masai grass. For foods ensiled (corn silage and sorghum silage) and (cane sugar) observed the values of $63.22 \%, 54.00 \%$ and $59.76 \%$ to the DIV of DM, respectively. There was no $(\mathrm{P}>0.05)$ change in value of the $\mathrm{pH}$ and of the concentration of ammonia nitrogen during the in vitro fermentation of forage plants. Thus, it is concluded that the value of the DIV of DM and parameters in vitro fermentation keeps similar to grasses of the same genus and ensiled forages during the dry season.
\end{abstract}

Key Words: fermentation $\mathrm{pH}$; ammonia nitrogen; supplementary roughage 


\section{INTRODUÇÃO}

O Brasil atualmente é detentor do maior rebanho bovino comercial do mundo e também maior exportador de carne bovina, destacando-se pelo menor custo de produção devido a grande maioria dos animais passarem parte ou todo o seu ciclo de produção a pasto. Segundo dados do Instituto Brasileiro de Geografia e Estatística IBGE (2012) até o ano de 2006, o Brasil possuía uma área aproximada de 158,75 milhões de hectares (ha) de pastagem onde pouco mais de 101,43 milhões de ha eram compostos de pastagens cultivadas.

No período da entressafra devido baixa precipitações, a qualidade e a produtividade das plantas forrageiras decaem não atendendo as exigências nutricionais dos animais o que acarreta em um baixo desempenho e na perda de peso corporal dos animais mantidos a pasto (Ribeiro et al., 2011).

Devido a esse déficit de alimentos volumosos, tanto em qualidade quanto em quantidade, alguns produtores investem na produção de silagem ou no cultivo de capineira (cana-de-açúcar e/ou capim-elefante) para tentarem suprir esse déficit alimentar no período seco do ano.

O conhecimento das exigências nutricionais de cada categoria animal e da composição química dos alimentos que serão consumidos por estes, são quesitos importantes para tornar-se um sistema de alimentação eficaz (Silva et al., 2008).

A análise química dos alimentos determina $o$ teor de nitrogênio e minerais e a avaliação bromatológica dos alimentos determina os grupos heterogêneos de compostos químicos, como os carboidratos totais, fibra em detergente neutro (FDN) e ácido (FDA) e carboidratos não fibrosos, além disso, a avaliação biológica determina 0 consumo e a digestibilidade de alimentos, onde existe a necessidade de utilização do animal ou bactéria (Lana, 2005).

A digestibilidade da dieta é na maioria das vezes estimada por métodos in vitro, simulando os processos de digestão no rúmen e obtendo-se maior precisão que sistemas in vivo. O que ocorre em sistemas in vivo é que os microrganismos e enzimas ali encontrados influenciam na digestão pelo fato de serem sensíveis a fatores indeterminados (Van Soest, 1994).

A determinação da digestibilidade dos alimentos pelo método in vitro apresenta diversas vantagens, sendo elas a anulação da influência do animal, a avaliação da função dos microrganismos correlacionados ao substrato de fermentação, a classificação das forragens e comparação dos alimentos que foram fornecidos aos ruminantes, entre outras vantagens (Lana, 2007).

A primeira etapa do processo de digestão in vitro, descrita por Silva e Queiroz (2002) e proposta por Baumgardt et al. (1962) é a pesagem da amostrada do alimento (em torno de 1 grama) em tubo de ensaio juntamente com $25 \mathrm{~mL}$ de saliva artificial e $25 \mathrm{~mL}$ de líquido ruminal (inóculo), após este procedimento é adicionado o dióxido de carbono (CO2) e incubado no banhomaria a $39^{\circ} \mathrm{C}$ por 24 a 48 horas.

$\mathrm{Na}$ sequência do estudo proposto por Baumgardt et al. (1962) os pesquisadores Tilley e Terry (1963) adicionaram uma segunda etapa (digestão enzimática) no método de um estágio (fermentação ruminal) para determinação da digestibilidade total in vitro (DIV).

A DIV da MS proporciona resultados mais acurados do que sistemas químicos, uma vez que simula um meio anaeróbico de degradação dos nutrientes, o que proporciona ação das enzimas microbiana e com isso a geração de dados mais próximos da 
digestibilidade in vivo (Mizubuti et al., 2009).

Desta maneira, objetivou-se avaliar a digestibilidade in vitro da matéria seca por meio da técnica de um estágio com 24 horas de incubação e os parâmetros da fermentação in vitro (valor de $\mathrm{pH}$ e concentração do nitrogênio amoniacal após 24 horas de fermentação) para as plantas forrageiras do mesmo gênero (capim-marandu vs capim-humidícola; capim-mombaça vs capim-massai) e para forrageiras ensiladas (silagem de milho vs silagem de sorgo vs capineira de cana-deaçúcar) no período seco do ano.

\section{MATERIAL E MÉTODOS}

O experimento foi realizado no Campus Universitário de Pontes e Lacerda, no Laboratório de Análise de Alimentos e Nutrição Animal (LAANA) e no Setor de Metabolismo Animal pertencentes à Universidade do Estado de Mato Grosso - UNEMAT.

Os alimentos analisados foram Brachiaria brizantha cv. Marandu; Brachiaria humidicola; Panicum maximum cv. Mombaça; Panicum maximum cv. Massai; silagem de milho (Zea mays); silagem de sorgo (Sorghum bicolor L. Moench); cana -de- açúcar (Saccharum officinarum L) picada in natura. As amostras foram coletadas no mês de setembro, período caracterizado pela seca na região Centro-Oeste do Brasil. As plantas forrageiras, assim como a capineira, apresentaram três anos de implantação e as silagens apresentaram seis meses de conservação (ensilagem).

As coletas das plantas forrageiras foram realizadas aleatoriamente com 0 auxílio de um quadro de ferro com $1 \mathrm{~m}^{2}$ de diâmetro, obtendo-se amostras representativas das forrageiras. As amostras das plantas forrageiras foram cortadas a $10 \mathrm{~cm}$ do solo, homogeneizadas, formando uma amostra média relativa de cada gênero e espécie.

As silagens, tanto de milho quanto de sorgo foram coletadas em diferentes pontos do silo, uma vez que a qualidade da silagem pode variar de um ponto para o outro no silo (Jobim et al., 2007).

A amostra de cana-de-açúcar foi coletada em diferentes pontos do vagão forrageiro, logo após o corte (processamento de picagem) da mesma. Os procedimentos de coleta das amostras seguiram a metodologia de acordo com Campos et al. (2004).

Foi utilizado um delineamento experimental inteiramente casualizado (DIC), sendo considerado como repetição de campo as baterias em número de três, para a determinação da digestibilidade in vitro (DIV) da MS das diferentes espécies forrageiras para 0 mesmo gênero ou para as forrageiras processadas (ensiladas ou picadas). Para cada bateria da DIV da MS foi utilizado três tubos para cada planta forragem e três tubos "brancos", os quais foram incubados ao mesmo tempo no banho-maria a 39o C.

Ante de proceder à incubação in vitro das plantas forrageiras, foi realizada a pré-secagens em estufa de ventilação forçada a $55^{\circ} \mathrm{C}$ das mesmas e em seguida foram homogeneizadas novamente e moídas em moinho tipo Willey com peneira de $1 \mathrm{~mm}$, sendo a amostra moída armazenada em potes plásticos com tampa (Silva e Queiroz, 2002) para posterior análise bromatológica e nutricional.

Os teores de fibra em detergente neutro (FDN) e fibra em detergente ácido (FDA) das plantas forrageiras foram obtidos pelo método do Filter Bag Technique (Ankom®) utilizando as soluções de detergentes neutro e/ou ácido de acordo com Van Soest et al. (1991), sem a utilização de sulfito de sódio e sem corrigir os valores de FDN e FDA com relação ao teor de matéria 
mineral da fibra segundo Geron et al. (2014a).

A matéria seca (MS) definitiva das plantas forrageiras foi realizada em estufa a $105^{\circ} \mathrm{C}$, a matéria mineral (MM) foi obtida pelo método por incineração em mufla a $600^{\circ} \mathrm{C}$, os teores de proteína bruta (PB) foram mensurados pelo método semi-micro-Kjeldahl utilizando 0 fator de conversão de 6,25 e o extrato etéreo (EE) foi determinado pela extração por lavagem com éter de petróleo, de acordo com Silva e Queiroz (2002).

A determinação dos carboidratos totais $(\mathrm{CHT})$ e carboidratos não estruturais (CNE) das plantas forrageiras foram obtidos pelas equações: $\mathrm{CHT}=\mathrm{MO}-(\mathrm{EE}+\mathrm{PB})$; $\mathrm{CNE}$ $=\mathrm{MO}-(\mathrm{PB}+\mathrm{EE}+\mathrm{FDN})$, de acordo com Sniffen et al.(1992). Os teores de fibra bruta (FB) seguiram as sugestões de Chandler (1990) citado pelo NRC (1996) onde as estimativas de FB foram obtidas pela seguinte equação: $\mathrm{FB}=$ FDA $\times 0,80$.

Os teores de nutrientes digestíveis totais (NDT) das plantas forrageiras foram obtidos pela equação proposta por NRC (1996), onde, NDT=105,2 - (0,68 x \%FDN $). \quad A$ equação para determinar o valor do extrativo não nitrogenado (ENN) das forragens seguiu a as recomendações de Silva e Queiroz (2002) onde: ENN = 100 - (MM+EE+FB+PB). A composição químico-bromatológica dos alimentos está demonstrada na Tabela 1.

Para a determinação da digestibilidade in vitro (DIV) da matéria seca (MS) das plantas forrageiras colhidas no período da seca foram utilizados dois cordeiros sem raça definida (SRD), inteiros, mantidos em gaiola de metabolismo, com peso corporal médio de $22,60+2,10 \mathrm{~kg}$, como doadores de líquido ruminal (inóculo). A coleta do inóculo seguiu a metodologia descrita por Geron et al. (2013) por meio de sonda esofágica.

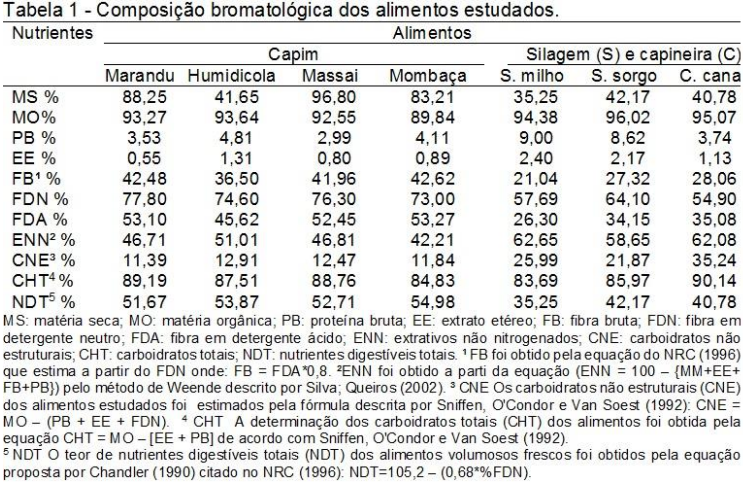

A ração ofertada aos cordeiros doadores de inóculo foi denominada de ração basal, a qual foi composta por $70 \%$ de volumoso (feno de capimmassai) e $30 \%$ de concentrado (grão de milho moído e farelo de soja). Os cordeiros receberam $5 \mathrm{~g}$ de mistura mineral comercial por refeição totalizando $10 \mathrm{~g}$ animal-1 dia-1. A mistura mineral foi composta por $120 \mathrm{~g}$ de $\mathrm{Ca} \mathrm{kg-1;50} \mathrm{mg} \mathrm{de} \mathrm{Co} \mathrm{kg-1;} 500$ mg de $\mathrm{Cu} \mathrm{kg-1;} 16 \mathrm{~g}$ de $\mathrm{S} \mathrm{kg-1;85} \mathrm{g}$ de $\mathrm{P}$ $\mathrm{kg}-1 ; 16$ mg de Se kg-1; $148 \mathrm{~g}$ de Na kg1 e $4.800 \mathrm{mg}$ de $\mathrm{Zn} \mathrm{kg}-1$ segundo 0 fabricante.

O consumo da ração basal dos cordeiros foi ad libitum de maneira que houvesse $10 \%$ de sobras, o arraçoamento ocorreu em duas refeições diárias às $7 \mathrm{~h}$ e às $17 \mathrm{~h}$. $A$ composição bromatológica da ração basal dos cordeiros doadores de inóculo está demonstrada na Tabela 2.

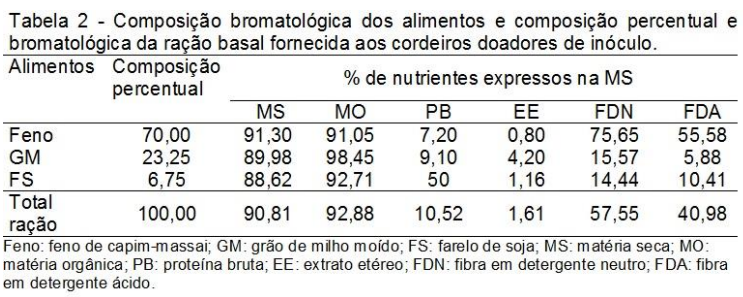

Para a determinação da DIV da MS foi utilizada a metodologia sugerida por Baumgardt et al. (1962), adaptada por Smith et al. (2010). A saliva artificial utilizada na incubação dos alimentos foi composta por três outras soluções distintas: a solução tampão de 
McDougall, solução de glicose e solução de ureia, sendo que para cada $300 \mathrm{~mL}$ de solução tampão, adicionava-se $5 \mathrm{~mL}$ de solução de glicose e $5 \mathrm{~mL}$ de solução de ureia.

Para o preparo da solução de McDougall utilizou-se um balão volumétrico de $1 \mathrm{~L}$, onde adicionou-se $9,80 \mathrm{~g}$ de carbonato de sódio anidro (NaHCO3), 3,71 g de fosfato de sódio bibásico anidro (Na2HPO4), 0,57 g de cloreto de potássio $(\mathrm{KCl}), 0,47 \mathrm{~g}$ de cloreto de sódio $(\mathrm{NaCl}), 0,12 \mathrm{~g}$ de sulfato de magnésio heptahidratado (MgSO4. $7 \mathrm{H} 2 \mathrm{O}$ ), 0,05 g de cloreto de cálcio dihidratado $(\mathrm{CaCl} 2$. $2 \mathrm{H} 2 \mathrm{O})$ e completou o volume do balão com água destilada até o menisco. As soluções de glicose e de ureia, foram composta por $5,5 \%$ de cada substância $(5,5 \mathrm{~g} 100 \mathrm{~mL}$ 1 de água destilada).

A pesagem das amostras das plantas forrageiras foi realizada em balança analítica, sendo o peso de aproximadamente $0,50 \mathrm{~g}$ de amostra seca ao ar (ASA) por tubo. No dia da incubação, providenciou a calibragem do valor do $\mathrm{pH}$ da saliva artificial, onde foi utilizado um béquer de $2 \mathrm{~L}$ contendo a saliva artificial no qual foi adicionado 0 dióxido de carbono $\left(\mathrm{CO}_{2}\right)$ até o $\mathrm{pH}$ da saliva ser estabilizado a aproximadamente 6,8.

Após a coleta de líquido ruminal (inóculo) dos cordeiros por meio de sonda esofágica foi adicionado $\mathrm{CO}_{2}$ dentro do kitassato para manter o ambiente em anaerobiose. No LAANA, o líquido ruminal foi filtrado com quatro camadas de gaze e em seguida transferido para um recipiente menor, para facilitar o manuseio e também para manter a temperatura $\left(39^{\circ} \mathrm{C}\right)$ e o ambiente anaeróbico constante. O inóculo antes da incubação apresentou um $\mathrm{pH}$ médio de 6,85 para as diferente baterias de fermentação in vitro e uma concentração média de $\mathrm{N}-\mathrm{NH} 3$ de 1,75 mg. $100 \mathrm{~mL}-1$ de conteúdo ruminal (inóculo).
No dia da coleta do inóculo foram mensurados os valores de $\mathrm{pH}$ do líquido ruminal além disso, foi retirada uma alíquota de $10 \mathrm{~mL}$ do inóculo, a qual foi acidificada com $0,2 \mathrm{~mL}$ ácido sulfúrico (H2SO4) em concentração 1:1 e congelada a $-10^{\circ} \mathrm{C}$ para posterior determinação de N-NH3 (amostra branco).

Foram acondicionados nos tubos $12,5 \mathrm{~mL}$ de inóculo e $37,5 \mathrm{~mL}$ de saliva artificial, assim como também nos tubos brancos (estes continham somente inóculo e saliva artificial) conforme adaptação proposta por Smith et al. (2010).

Após adicionar o inóculo e a saliva artificial, acrescentou-se o $\mathrm{CO}_{2}$ na superfície dos tubos para a remoção do oxigênio $\left(\mathrm{O}_{2}\right)$ e imediatamente estes foram tampados com rolha de borracha equipada com válvula de Bünsen. Em seguida os tubos foram incubados em aparelho de banho-maria tipo Dubnoff (digital microprocessado, com aquecedor automático, mod. Q226 M1 Quimis $\left.{ }^{\circledR}\right)$, contendo no seu interior água a uma temperatura de $39,2^{\circ} \mathrm{C}$.

Após 24 horas de incubação, a fermentação foi interrompida, por meio da imersão dos tubos de ensaio em gelo moído durante 10 minutos. O conteúdo dos tubos foi filtrado em papel filtro quantitativo (faixa preta, com diâmetro $15 \mathrm{~cm}$ para filtração rápida para precipitados grossos e gelatinosos), o líquido ruminal filtrado foi armazenado para posterior análise (concentração de nitrogênio amoniacal), e os filtros com os resíduos foram colocados em estufa, a $105^{\circ} \mathrm{C}$, onde permaneceram por 24 horas. Após este período, os filtros foram colocados em um dessecador para posterior pesagem.

Logos após a filtragem do conteúdo dos tubos, o líquido filtrado de cada tratamento experimental foi homogeneizado e com potenciômetro de bancada foram mensurados os valores de $\mathrm{pH}$ do líquido ruminal, após 
24 horas de incubação in vitro. Em seguida $10 \mathrm{~mL}$ do fluído filtrado foi acidificado com H2SO4 (1:1) e congelado para posteriormente realizar determinação do nitrogênio amoniacal (N-NH3). Para determinação das concentrações de $\mathrm{N}-\mathrm{NH} 3$ do líquido ruminal, o líquido foi descongelado $e$ centrifugado a 3.000 rpm por 5 minutos, de acordo com a metodologia proposta por Preston (1995), onde se realizou a destilação com $\mathrm{KOH}$ a 2 mol L-1 conforme descrito por Alves et al. (2012).

Após a filtragem do material fermentado, os filtros com o resíduo foram encaminhados para estufa a 105 ${ }^{\circ} \mathrm{C}$ por 4 horas e depois pesados. Por diferença de peso, obtiveram-se os valores da digestibilidade in vitro da MS pela seguinte formula: DIV da MS $=\{[$ PA - (PR-PT)] / PA\} x 100, onde: PA é o peso da amostra ( $g$ de $M S$ ); $P R$ é o peso do resíduo (g de MS); PT é o peso (g) do resíduo do tubo branco.

A análise estatística das variáveis estudadas foi interpretada no Sistema de Análises Estatísticas e Genéticas (SAEG) por meio de análise de variância (UFV, 2009) utilizando o seguinte modelo matemático: $Y \mathrm{ij}=\mu+\mathrm{Fi}$ + eij, em que: Yij = valor observado para as variáveis analisada em função da planta forrageira i na repetição j; $\mu=$ média geral; $\mathrm{Fi}=$ efeito das diferentes plantas forrageiras (diferentes espécies dentro do mesmo gênero ou dos volumosos suplementares) $=\mathrm{i}$. eij $=$ erro aleatório associado a cada observação. Quando observada diferença para as variáveis estudadas na análise de variância aplicou-se o teste de Tukey, considerando $5 \%$ de significância para os capins do mesmo gênero ou para as forrageiras ensiladas.

\section{RESULTADOS E DISCUSSÃO}

Não houve diferença $(P>0,05)$ no valor de DIV da MS as plantas forrageiras do gênero Brachiaria (Tabela 3). Os valores de DIV da MS do capimmarandu e humidícola foram de $48,40 \%$ e 51,21\%, respectivamente. Foi observada uma amplitude de $5,42 \%$ nos dados de DIV da MS entre as diferentes espécies de Brachiaria (marandu e humidícola), esta variação pode ser devido a amplitude na composição química e bromatológia (Tabela 1) destes capins, principalmente o teor de FDN e FDA.

De acordo com Valadares Filho et al. (2010), o valor de PB do capimmarandu foi de $7,24 \%$, a qual foi superior ao encontrado no presente estudo de $3,53 \%$, para os teores de FDN $(70,94 \%)$ e FDA $(37,28 \%)$ esses autores encontraram valores menores ao do presente estudo de $80,36 \%$ de FDN e 48,62\% FDA, respectivamente, esta variação na composição bromatológica dos capins provavelmente está correlacionado a época de colheita da forrageira.

Estudo realizado por Toro Velazques et al. (2010), para avaliar diferentes forrageiras tropicais em diferentes idades de corte, demonstrou que o capim-marandu cortado aos 42 dias, nos meses de abril e junho apresentou um valor de DIV da MS de $56,86 \%$, sendo que a composição bromatológica apresentou teor de 9,88\% de $\mathrm{PB}, 65,70 \%$ de FDN e $32,89 \%$ de FDA.

Estudo realizado por Geron et al. (2014b) para avaliar a digestibilidade in vitro dos nutrientes e parâmetros da fermentação de dietas contendo diferentes níveis de concentrado (20\%, $40 \%, 60 \%$ e $80 \%$ ) utilizando o inoculo de ovinos, demonstrou que o DIV da MS apresentou um valor médio de 59,74\% $(p>0,05)$ para os diferentes níveis de concentrado na dieta. Os autores observaram que para a dieta contendo 
$80 \%$ de silagem de milho e $20 \%$ de concentrado o valor da DIV da MS foi de $59,98 \%$, valor semelhante ao observado no presente estudo para a silagem de milho de 63,22\% (Tabela 3).

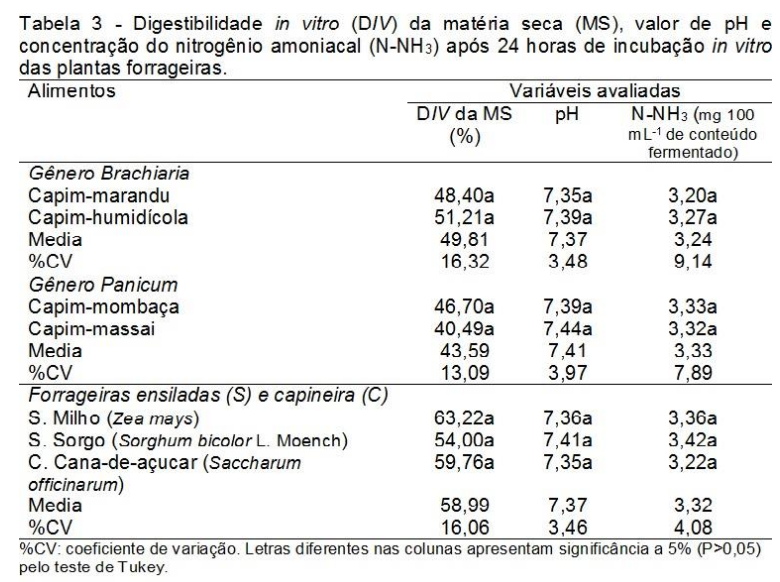

Os valores observados para a DIV da MS para as diferentes plantas forrageiras pode ter sido influenciada pelo tempo de incubação (24 horas), além disso, o valor de $\mathrm{pH}$ do conteúdo fermentado (Tabela 3) durante o processo de incubação in vitro ficou acima da faixa ideal 6,2 a 6,8 recomendada para a máxima eficiência fermentativa, o que pode ter interferido na digestão da MS das forrageiras (Maeda et al., 2011). Segundo estudo realizado por Zeoula et al. (2011), a atividade máxima de organismos celulolíticos no rúmen deve ocorrer em um $\mathrm{pH}$ variando de 6,0 e 6,8 , os mesmos valores se aplicam nos estudos in vitro (Geron et al., 2014b).

Estudo realizado por Silva et al. (2004), para testar diferentes métodos de recuperação de pastagens do gênero Brachiaria no agreste pernambucano, demonstrou que o capim-humidícola coletado antes da aplicação de adubo químico apresentou uma DIV da MS de $30,63 \%$, sendo que o mesmas apresentou teores de PB, FDN e FDA de $7,73 \% ; \quad 72,59 \%$ e $38,68 \%$, respectivamente.

Em trabalho comparando quatro diferentes espécies de gramíneas forrageiras do gênero Brachiaria, Lopes et al. (2010) obtiveram uma DIV da MS de $62,50 \%$ para o capim-marandu e $59,30 \%$ para o capim-humidícola, valores acima do encontrado no presente estudo de $48,40 \%$ e $51,21 \%$, respectivamente. Provavelmente essa diferença na DIV da MS para o gênero Brachiaria pode ser devido a qualidade da forragem, os valores de PB para os capins marandu e humidícola, de $7,50 \%$ e 6,80\%, respectivamente observado por Lopes et al. (2010) foram superiores ao encontrado no presente estudo de $3,53 \%$ e $4,81 \%$, respectivamente. Para os teores de FDN e FDA o estudo de Lopes et al. (2010) demonstrou valores de $66,80 \%$ de FDN e $36,80 \%$ de FDA para o capim-marandu e $73,40 \%$ de FDN e $38,20 \%$ de FDA para o capimhumidícola, valores inferiores aos observados no presente estudo de $80,36 \%$ e $48,62 \%$, respectivamente 0 capim-marandu e de $75,51 \%$ e $44,29 \%$, respectivamente, para o capimhumidícola (Tabela 1).

Os valores de DIV da MS para as plantas forrageiras do gênero Panicum não apresentaram $(P>0,05)$ diferença entre si, sendo observado valor de $46,70 \%$ para o capim-mombaça e de $40,49 \%$ para o capim-massai (Tabela 3 ). Entretanto, foi observado uma amplitude de $13,30 \%$ na DIV da MS entre as diferentes espécies de Panicum (mombaça e massai), esta variação pode ter sido influenciada pela morfologia das espécies (cultivares), além da variação na composição bromatológica entre os capins do gênero Panicum (Tabela 1).

A qualidade nutricional de diferentes espécies gênero Panicum avaliada por Stabile et al. (2010), indicou que o capim-mombaça colhido aos noventa dias de diferimento apresentou uma DIV da MS de 38,90\% no colmo e $51,00 \%$ na folha e, para o capim-massai uma DIV da MS de $43,90 \%$ e $54,20 \%$, respectivamente no colmo e na folha. Os autores obtiveram 
um valor médio de DIV da MS de $44,95 \%$ e $49,05 \%$ para a planta inteira dos respectivos capins. Esses resultados de DIV da MS obtidos por Stabile et al. (2010), ficaram próximos aos observados no presente estudo de $46,70 \%$ para o capim-mombaça e superior para o capim-massai de 40,49\% (Tabela 3).

Estudos realizados com capimmombaça segundo Groff et al. (1998) e Duque et al. (2011) apresentaram respectivamente valores de $55,8 \%$ e $65,6 \%$ de DIV da MS; $10,2 \%$ e $13,0 \%$ de PB; $64,0 \%$ e $69,7 \%$ de FDN; $41,7 \%$ e $40,5 \%$ de FDA, respectivamente. Este fato provavelmente pode ter ocorrido devido a menor qualidade da forragem do presente estudo, a qual foi amostrada no período da seca.

Para os valores de DIV da MS das forrageiras ensiladas (silagem de milho e silagem de sorgo) e capineira (cana-de-açúcar in natura) não observou $(P>0,05)$ diferença na DIV da MS com valores de 63,22\%, 54,00\% e $59,76 \%$, respectivamente. Entretanto pode ser observada uma amplitude de $13,30 \%$ nos dados de DIV da MS entre a silagem de milho e a capineira, essa variação pode ser em função das diferenças morfogênicas entre as espécies forrageiras, além da variação na composição bromatológica (Tabela 1) dos volumosos ensilados e capineira.

A determinação da DIV da MS da silagem de milho realizada por diferentes metodologias segundo Lopes et al. (2010) apresentou um valor médio $60,13 \%$, pela metodologia proposta por Tilley e Terry (1963) e um teor médio de $9,88 \%$ de $\mathrm{PB}, 46,78 \%$ de FDN, 38,58\% de FDA.

Estudo conduzido por Cabral et al. (2003), para avaliar a silagem de sorgo com diferentes proporções de panículas, demonstrou que nas amostras de sorgo com $60 \%$ de panículas o teor de MS foi de 40,96\%, o que se aproximou do encontrado neste estudo $(42,17 \%$ de MS). Os autores relataram um teor de PB de $8,21 \%$ e $43,40 \%$ de FDN e observaram que a DIV da MS foi de $69,19 \%$, a qual foi superior ao observado no presente estudo $(54,00 \%)$.

Com o objetivo de estudar o tratamento da cana-de-açúcar com cal virgem ou cal hidratada e sua influência na composição bromatológica deste volumoso, Mota et al. (2010) encontraram valores de $2,65 \%, 45,25 \%$, $19,66 \%$ e $58,28 \%$ para PB, FDN, FDA e DIV da MS, respectivamente para a cana-de-açúcar tratada com cal, os quais foram semelhantes ao observado no presente estudo.

Estudo realizado para avaliar o efeito da inclusão de aditivos na ensilagem da cana-de-açúcar, foi conduzido por Schmidt et al. (2005), os quais encontraram nas amostras de cana-de-açúcar in natura teor de 3,43\% de PB, $55,50 \%$ de FDN, $37,40 \%$ de FDA e uma DIV da MS de $51,30 \%$, sendo os valores de DIV da MS inferiores ao obtido no presente estudo (59,76\%), provavelmente devido as diferenças na composição bromatológica entre os ensaios.

Os valores de DIV da MS para os diferentes gêneros de capins e plantas forrageiras ensiladas observados no presente estudo apresentaram variações em relação a literatura, provavelmente esta diferença observada entre os estudos deve-se a qualidade dos alimentos volumosos analisados e a metodologia utilizadas para obtenção dos coeficientes de digestibilidade (in vivo e in vitro).

O presente estudo sugere que 0 valor nutricional dos diferentes capins pertencentes ao mesmo gênero ou submetidos a processo de conservação (ensilagem ou capineira) apresentou uma digestibilidade in vitro da MS semelhante entre si, desta maneira os produtores poderão optar pela planta forrageira de maior produção e que 
melhor se adapta as condições climáticas da região tropical, uma vez que no período da seca o valor nutricional das forrageiras avaliadas no presente estudo se equivaleram, assim o aporte de MS digestível destes capins fornecem matéria orgânica necessária para a fermentação ruminal e podem propiciar desenvolvimento satisfatório da microbiota ruminal e consequentemente do animal hospedeiro.

As diferentes espécies de capins do mesmo gênero não alteraram $(\mathrm{P}>0,05)$ o valor de $\mathrm{pH}$ do líquido ruminal após 24 horas de incubação in vitro (Tabela 3). Foi observado que todos os gêneros das plantas forrageiras avaliadas apresentaram valores acima de 7,0 para $0 \mathrm{pH}$ do líquido ruminal após 24 horas de incubação. Esse fato pode ter afetado a DIV da MS devido estar acima dos parâmetros para máxima atividade dos organismos celulolíticos no rúmen, que ocorreria numa faixa de 6,0 a 6,8 , conforme Geron et al. (2008).

Estudo realizado por Geron et al. (2014b), para avaliar a DIV da MS e parâmetros fermentativos de rações com níveis crescentes de concentrado demonstrou que o valor médio do $\mathrm{pH}$ foi de 7,40, independentemente do nível de concertado (20\%, 40\%, 60\% e $80 \%$ ) utilizado na formulação da dieta. Normalmente nos estudos in vivo sobre os parâmetros ruminais observa-se menor valor de $\mathrm{pH}$ do líquido ruminal em relação ao estudo in vitro, este fato pode ser devido a dinâmica de absorção de ácidos graxos voláteis e nitrogênio amoniacal no rúmen, o que não ocorre nos estudos in vitro.

Os valores médio de $\mathrm{pH}$ do líquido ruminal após 24 horas de incubação foi de 7,38. Entretanto, estudo realizado por Vieira et al. (2007), para avaliar a característica do líquido ruminal de ovinos Santa Inês criados extensivamente em Pernambuco demonstrou um valor de $\mathrm{pH}$ do líquido ruminal de 6,76. Da mesma maneira estudo conduzido por Cardoso et al. (2000) indicou que os valores de $\mathrm{pH}$ do líquido ruminal de novilhos variaram de 5,76 a 6,83, nos tempos $0,2,4,6$ e 8 horas após a alimentação dos animais.

A concentração do $\mathrm{N}-\mathrm{NH} 3$ do líquido ruminal após 24 horas de incubação in vitro não apresentou alteração $(P>0,05)$ entre as espécies de capins do mesmo gênero ou de plantas forrageiras ensiladas (Tabela 3). As concentrações de $\mathrm{N}-\mathrm{NH} 3$ do líquido ruminal após 24 horas de incubação variaram de 3,20 a 3,42 mg de N-NH3 $100 \mathrm{~mL}-1$ de conteúdo fermentado para todas as plantas forrageiras avaliadas. Este valores observados da concentração do $\mathrm{N}-\mathrm{NH} 3$ do conteúdo fermentado está abaixo dos valores descritos por Prado et al. (2010), em que animais recebendo a ração controle (relação V:C de 80:20 e contendo 11,1\% de PB, $55,1 \%$ de FDN e $31,4 \%$ de FDA) obtiveram uma concentração de 10,83 $\mathrm{mg}$ de $\mathrm{N}-\mathrm{NH} 3100 \mathrm{~mL}-1$ de líquido ruminal.

As baixas concentrações de $\mathrm{N}$ $\mathrm{NH} 3$ após $24 \mathrm{~h}$ de fermentação pode ter se dado, devido às baixas concentrações de N-NH3 no inóculo, tendo em vista que a concentração médias antes da incubação foi de 1,75 mg de N-NH3 100 mL-1 de do conteúdo ruminal.

De acordo com Geron et al. (2014b), os diferentes níveis de concentrado nas rações experimentais de ovinos alteraram $(\mathrm{P}<0,05)$ de maneira quadrática a concentração de nitrogênio amoniacal (N-NH3) do conteúdo fermentado após a incubação in vitro por 24 horas. 0 ponto de máximo para a concentração de $\mathrm{N}-\mathrm{NH} 3$ obtido pela equação foi de $3,82 \mathrm{mg}$ de $\mathrm{N}-\mathrm{NH} 3 \quad 100 \mathrm{~mL}-1$ de conteúdo fermentado estimado para o nível de $37 \%$ de concentrado. Observa-se que a concentração máxima de N-NH3 
encontrada pelos autores foi para 0 nível de $37 \%$ de concentrado na dieta, o qual foi semelhante ao observado no presente estudo utilizando apenas alimento volumoso (plantas forrageiras).

Verificou-se que os valores médios para a concentração do N-NH3 do conteúdo fermentado após a incubação in vitro de 24 horas $(3,30 \mathrm{mg}$ $100 \mathrm{~mL}-1$ de conteúdo fermentado) das diferentes plantas forrageiras avaliadas, mantiveram-se abaixo da faixa proposta por Mehrez et al. (1977) e Geron et al. (2006), os quais afirmaram que a máxima atividade fermentativa ruminal é obtida quando o $\mathrm{N}-\mathrm{NH} 3$ alcança valores entre 19 e $23 \mathrm{mg} 100 \mathrm{~mL}-1$ de líquido ruminal. Assim, a concentração média do N-NH3 do conteúdo fermentado após 24 horas de incubação in vitro, mantevese abaixo da concentração obtida por Satter \& Roffler (1975) e Geron et al., (2008) de $5 \mathrm{mg} 100 \mathrm{~mL}-1$ de líquido ruminal, para que a mesma não limitasse 0 crescimento microbiano, portanto este fator pode ter interferido no processo de digestibilidade da MS das diferentes plantas forrageiras avaliadas no presente estudo.

Segundo Yoshimura (2012), em estudo in vitro da digestibilidade da MS de rações contendo aditivos a base de monesina sódica e própolis com $70 \%$ de volumoso, observaram que valores de concentração de nitrogênio amoniacal do líquido ruminal após 24 horas de incubação variou de 5,58 a 7,63 mg 100 $\mathrm{mL}-1$ para as rações contendo os diferentes aditivos a base de própolis e monensina sódica. Estes valores observados para a concentração de N$\mathrm{NH} 3$ do líquido ruminal após 24 horas de incubação no estudo de Yoshimura (2012), pode ser devido ao teor de PB das dietas serem de 13,6\%, valor superior ao da PB das plantas forrageiras avaliadas no presente estudo (Tabela 1).

\section{CONCLUSÕES}

A digestibilidade in vitro da MS para as diferentes capins do mesmo gênero ou das plantas forrageiras ensiladas não apresentaram alterações entre si para o período da seca na região Centro-Oeste do Brasil.

A metodologia da digestão in vitro da matéria seca pode ser utilizada na avaliação do valor nutricional de forrageiras, por apresentar dados que corroboram com os encontrados na literatura em estudo in vivo.

\section{AGRADECIMENTOS}

A Universidade do Estado de Mato Grosso (UNEMAT) - Campus de Universitário de Pontes e Lacerda, por ter apoiado e auxiliado no desenvolvimento desta pesquisa cedendo os equipamentos do Laboratório de Análise de Alimentos e Nutrição Animal (LAANA).

\section{REFERÊNCIAS}

ALVES, E. M.; PEDREIRA, M. S.; PEREIRA, M. L. A.; et al. Farelo da vagem de algaroba associado a níveis de ureia na alimentação de ovinos: balanço de nitrogênio, $\mathrm{N}$-ureico no plasma e parâmetros ruminais. Acta Scientiarum. Animal Sciences, v. 34, n. 3, p. 287-295, 2012.

BAUMGARDT, B.R., CASON, J.L.; TAYLOR, M. W. Evaluation of forages in the laboratory: I. Comparative accuracy of several methods. Journal of Dairy Science, v.45, n.1, p.59-61, 1962.

CABRAL, L.S.; VALADARES FILHO, S.C.; DETMANN, E.; et al. Composição químicobromatológica, produção de gás, digestibilidade in vitro da matéria seca e NDT estimado da silagem de sorgo com diferentes proporções de panículas. Revista Brasileira de Zootecnia, v. 32, n. 5, p. 1250-1258, mai. 2003.

CAMPOS, F. P.; NUSSIO, C. M. B.; NUSSIO, L. G. Métodos de análise de alimentos. Piracicaba, SP: FEALQ, 2004. $135 \mathrm{p}$.

CARDOSO, R. C.; VALADARES FILHO, S. C.; SILVA, J. F. C.; et al. Sintese Microbiana, pH, 
Concentrações de Amônia Ruminal e Balanço de Compostos Nitrogenados, em Novilhos F1 Limousin $x$ Nelore. Revista Brasileira de Zootecnia, v. 29, n. 6, p. 1844-1852, jun. 2000.

CHANDLER, P. Energy prediction of feeds by forage testing explored. Feed stuffs, v.62, n.36, p.12-18, 1990.

DUQUE, A.C.A.; LOPES, F.C. .; DORNELLAS, R.A.C.; et al. Digestibilidade da matéria seca de alimentos volumosos e concentrados, determinada por diferentes procedimentos in vitro. Revista Brasileira de Saúde e Produção Animal, Salvador, v. 12, n. 3, p. 680-690, jul/set. 2011.

GERON, L.J.V.; ZEOULA, L.M.; VIDOTTI, R.M.; et al. Digestibilidade e parâmetros ruminais de rações contend silagens de resíduo da filetagem de tilápia. Acta Scientiarum. Animal Science, v.28, n.4, p.437-445, 2006.

GERON, LJ.V.; ZEOULA, L.M.; ERKEL, J.A.; et al. Coeficiente de digestibilidade e características ruminais de bovinos alimentados com rações contendo resíduo de cervejaria fermentado. Revista Brasileira de Zootecnia, v.37, n.9, p.1685-1695, 2008.

GERON, L.J.V.; MEXIA, A.A.; CRISTO, R.L.; et al. Consumo, digestibilidade dos nutrientes e características ruminais de cordeiros alimentados com níveis crescentes de concentrado em ambiente tropical no Vale do Alto Guaporé -MT. Semina: Ciências Agrarias, v.34, n.5, p.2497-2510, 2013.

GERON, L.J.V.; CABRAL, L.S.; TRAUTMANNMACHADO, R.J.; et al. Avaliação do teor de fibra em detergente neutro e ácido por meio dediferentes procedimentos aplicados às plantas forrageiras. Semina: Ciências Agrárias, v. 35, n. 3, p. 1533-1542, 2014a.

GERON, L.J.V.; TRAUTMANN-MACHADO, R.J.; GARCIA, J.; et al. Coeficiente de digestibilidade in vitro da matéria seca e parâmetros fermentativos de rações com níveis crescentes de concentrado. Revista de Ciências AgroAmbientais, v.12, n.1, p. , 2014b.

GROFF, A. M.; CECATO, U.; MIRA, R. T.; et al. Avaliação da composição química e DIVMS de cultivares e acessos de Panicum maximum Jacq. Sob duas alturas de corte. Revista Brasileira de Zootecnia, v. 27, n. 5, p. 10571063, mai. 1998.

IBGE - Instituto Brasileiro de Geografia e Estatística. Disponível em: <http://seriesestatisticas.ibge.gov.br/series.aspx ?vcodigo=AGRO03\&sv=1\&t=utilizacao-das terras-ha> Acesso em: 30 mar. 2012.
JOBIM, C.C.; NUSSIO, L.G.; REIS, R.A. et al. Avanços metodológicos na avaliação da qualidade da forragem conservada. Revista Brasileira de Zootecnia, Viçosa, v. 36, [s. n.], p. 101-119, 2007 (Suplemento Especial).

LANA, R. P. Nutrição e alimentação animal (mitos e realidades). Viçosa, MG: Edição $1^{\circ}$, Editora UFV, 2005, 344p.

LOPES, F.C.F.; DORNELAS, R.A.C.; PORTUGAL, J.A.B.; et al. Digestibilidade da matéria seca de silagens de milho e de suplementos concentrados determinada por procedimentos in vitro. Arquivo Brasileiro de Medicina Veterinária e Zootecnia, v. 62, n. 5, p. 1167-1173, set./out. 2010.

MAEDA, E.M.; ZEOULA, L.M.; JOBIM, C.C.; et al. Chemical composition, fermentation, in vitro digestibility and in situ degradability of sugar cane silages with lactobacillus, urea and agricultural byproduct. Revista Brasileira de Zootecnia,v.40, n.12, p.2866-2877, 2011.

MEHREZ, A.Z.; ORSKOV, E.R.;I. et al. Rates of rumen fermentation in relation to ammonia concentration. Bristsh Journal of Nutrition, v.38, n.3, p.437-443, 1977.

MIZUBUTI, I.Y.; PINTO, A.P.; RAMOS, B.M.O.; et al Métodos laboratoriais de avaliação de alimentos para animais. Londrina, PR: EDUEL, 2009. 228 p.

MOTA, D.A.; OLIVEIRA, M.D.S.; DOMINGUES, F.N.; et al. Hidrólise da cana-de-açúcar com cal virgem ou cal hidratada. Revista Brasileira de Zootecnia, v. 39, n. 6, p. 1186-1190, jun. 2010.

NATIONAL RESEARCH COUNCIL - NRC. Nutrient requeriment of beef cattle. 7. ed. Washington: National Academy Press., 242 pp. 1996.

PRADO, O.P.P.; ZEOULA, L.M.; MOURA, L.P.P.; et al. Efeito da adição de própolis e monensina sódica na digestibilidade e características ruminais em bubalinos alimentados com dieta à base de forragem. Revista Brasileira de Zootecnia, v. 39, n. 9, p. 2055-2065, set. 2010.

PRESTON, T.R. Biological and chemical analytical methods. In: PRESTON, T.R. Tropical animal feeding: a manual for research workers. Rome: FAO, p.191- 264, 1995.

RIBEIRO, O.L.; CECATO, U.; IWAMOTO, B.S.; et al. Desempenho de bovinos em capimtanzânia adubado com nitrogênio ou consorciado com Estilosantes. Revista Brasileira de Saúde e Produção Animal, v. 12, n. 1, p. 275285, jan./mar. 2011. 
SATTER, L.D.; ROFFLER, R.E. Relationship between ruminal ammonia and nonprotein nitrogen utilization by ruminants. 1 . Development of a model for predicting nonprotein nitrogen utilization by catte. Jounal of Dariry Science, Champaign, v.58, n.12, p.1880-1888, 1975.

SCHMIDT, P.; MARI, L.J.; NUSSIO, L.G.; et al. Aditivos químicos e biológicos na ensilagem de cana-de-açúcar. 1. Composição química das silagens, ingestão, digestibilidade e comportamento ingestivo. Revista Brasileira de Zootecnia, v. 36, n. 5, p. 1666-1675, 2005 (Suplemento).

SILVA, D.J.; QUEIROZ. A.C. Análise de alimentos (Métodos químicos e biológicos). 2a ed., Viçosa: UFV, 2002. 178 p.

SILVA, M.C.; SANTOS, M.V.F.; DUBEUX JUNIOR, J.C.B.; et al. Avaliação de métodos para recuperação de pastagens de braquiária no agreste de Pernambuco. 2. Valor nutritivo da forragem. Revista Brasileira de Zootecnia, Viçosa, v.33, n.6, p. 2007-2016, jun. 2004 (Suplemento 2).

SILVA, R.W.S.M.; OLIVEIRA, J.C.P.; EGGLETON, C.M.J.; et al. Manejo da alimentação. In: SALOMONI, E. Sistema de Criação de Bovinos de Leite para a Região Sudoeste do Rio Grande do Sul. Rio Grande do Sul: Embrapa, 2008.

SMITH, D.R., DILORENZO, N., LEIBOVICH, J.; et al. Effects of sulfur and monensin concentrations on in vitro dry matter disappearance, hydrogen sulfide production, and volatile fatty acid concentrations in batch culture ruminal fermentations. Jornal of Animal Science, v.88, p.1503-1512, 2010.

SNIFFEN, C.J.; O'CONNOR, J.D.; VAN SOEST, P.J. A net carbohydrate and protein system for evaluating cattle diets II. Carbohydrate and protein availability. Journal of Animal Science, v.70, n.11, p.3562-3577, 1992.

STABILE, S.S.; SALAZAR, R.R.; JANK, L.; et al. Características de produção e qualidade nutricional de genótipos de capim-colonião colhidos em três estádios de maturidade. Revista Brasileira de Zootecnia, v. 39, n. 7, p. 1418-1428, 2010.

TILLEY, J.M.A.; TERRY, R.A. A two-stage technique for the in vitro digestion of forage crop. Journal British Grassland Society, v.18, n.2, p.104-111, 1963.

TORO VELAZQUES, P.A.; BERCHIELLI, T.T.; REIS, R. A.; et al. Composição química, fracionamento de carboidratos e proteínas e digestibilidade in vitro de forrageiras tropicais em diferentes idades de corte. Revista Brasileira de Zootecnia, v. 39, n. 6, p. 1206-1213, 2010.

UNIVERSIDADE FEDERAL DE VIÇOSA - UFV. Sistema de análises estatísticas - SAEG. Viçosa: UFV. 287p. 2009. (Manual do usuário).

VALADARES FILHO, S.C.; MACHADO, P.A.S.; CHIZZOTTI, M.L. et al. Tabelas brasileiras de composição de alimentos para bovinos. 3. ed. Viçosa, MG:UFV/DZO, 2010, 520 p.

VAN SOEST, P.J.; ROBERTSON, J.B.; LEWIS, B.A. Methods for dietary fiber, neutral detergent fiber, and nonstarch polysaccharides in relation to animal nutrition. Journal of Dairy Science, Savoy, v.74, n.12, p.3583-3597, 1991.

VAN SOEST, P.J. Ecologia nutricional dos ruminantes. 2 ed, Rio de Janeiro: Constock Publishing Associates. 1994. 476p.

VIEIRA, A.C.S.; AFONSO, J.A.B.; MENDONÇA, C.L. Características do fluído ruminal de ovinos Santa Inês criados extensivamente em Pernambuco. Pesquisa Veterinária Brasileira, v. 27, n. 3, p. 110-114, 2007.

YOSHIMURA, E.H. Aditivos à base de própolis na alimentação de bovinos: estudos in vitro e in vivo. 2012. p.47. Dissertação (mestrado) Universidade Estadual de Maringá - UEM. Maringá, 2012.

ZEOULA, L.M.; BELEZE, J.R.F.; MAEDA, et al. Levedura ou monensina na dieta de bovinos $e$ bubalinos sobre a fermentação ruminal e efiência microbiana. Acta Scientiaurum. Animal Science, v.33, n.4, p.379-386, 2011. 